\title{
ANEURYSMS OF THE ASCENDING AORTA DUE TO MEDIAL DEGENERATION ASSOCIATED WITH ARACHNODACTYLY (MARFAN'S DISEASE)
}

\author{
BY \\ J. C. SLOPER AND GEOFFREY STOREY \\ From the Bernhard Baron Institute of Pathology, and the Cardiac Depariment, the London Hospital
}

(RECEIVED FOR PUBLICATION, MARCH 15, 1953)

Two cases are described of women showing aneurysm of the ascending aorta due to medial degeneration. In both there was evidence of Marfan's (1896) “dolichostenomélie" (arachnodactyly), a condition which in its fully developed form includes, as well as long, thin fingers and limbs, such changes as joint hyperextensibility, dolichocephaly, and dislocation of the optic lens (Rados, 1942).

Severe aortic medial degeneration has been reported in some 25 cases of this disease (Marvel and Genovese, 1951), causing in some dissecting aneurysms and in others true aneurysms of the aortic arch. Because non-syphilitic aneurysms of the latter kind are rare, it is tempting to regard them all as manifestations of either latent or overt Marfan's disease ( $\boldsymbol{R}$ ywlin, 1952). This we hold, at least in older people, to be a mistaken view, since in old age there is commonly a non-specific medial degeneration which can give rise to aneurysm of the aortic arch (Turnbull, 1915; Rottino, 1939). Such cases, however, lack the additional cardiac abnormalities frequently encountered in Marfan's disease, and it is the combination of cardiac and aortic lesions which we regard as diagnostic of the latter, even in its incomplete form.

\section{Case Reports}

Case 1.-A woman, aged 24 years, had been seen 12 years earlier (1938) by Dr. William Evans, when a systolic murmur was heard at the left sternal edge. There was no aortic incompetence, but cardioscopy showed prominence of the ascending aorta and the aortic knuckle.

When seen in January, 1950, she gave a three months' history of attacks of stabbing pain in the left chest, unrelated to exertion or other known cause. An operation had been performed six months previously for detachment of the retina. There was bilateral dislocation of the optic lenses. She had arachnodactyly, long thin fingers, hyperextensibility of joints, dolichocephaly, and a high, arched palate. Other abnormal signs were confined to the cardio- vascular system. The blood pressure was $180 / 40 \mathrm{~mm}$. $\mathrm{Hg}$; the pulse was regular and collapsing; the pulsation in the femoral arteries was normal. The apex beat was in the anterior axillary line. A soft systolic murmur and a loud and rough early diastolic murmur were heard in all areas, although loudest at the left sternal edge, where a diastolic thrill was felt. Radiologically there was enlargement of the left ventricle and an abnormal prominence in the region of the pulmonary artery. The arch of the aorta, although high, was not apparently dilated. A barium swallow showed displacement of the oesophagus to the right. The cardiogram showed left ventricular preponderance and the effects of rotation. The $T$ wave was inverted in leads II, III, and $\mathrm{CR}_{\bar{i}}$. At first there were no signs of heart failure, but she soon became short of breath on exertion and had nocturnal dyspnoea. She was admitted to hospital and treated with rest, diminished fluid and salt intake, mercurial diuretics, and digitalization. There was no response to these measures, and five days later, three weeks after the onset of heart failure, she died.

Relevant Findings at Necropsy (P.M. 76, 1950).Necropsy was performed about 15 hours after death, and the chief findings were heart failure, aortic incompetence, aneurysm of the ascending aorta, arachnodactyly, and dislocation of the optic lens.

The body was that of a slender woman with long digits (middle finger, $11.5 \mathrm{~cm}$. long, second toe, $5 \mathrm{~cm}$., carpus and metacarpus, $12 \mathrm{~cm}$.). The lens of the right eye was lying in the optic cup, and the retina was folded but adherent to the choroid. The endocrine glands were normal.

There was a recent infarct $(1 \mathrm{~cm}$. diameter) in the right lung, severe oedema of the lungs, and serous pleural effusions $(300 \mathrm{ml}$. in each sac). There was back-pressure congestion of the abdominal organs, and pitting oedema of the legs.

Weights were as follows: body, $53.6 \mathrm{~kg}$. (length, $1.74 \mathrm{~m}$.) ; heart and aneurysm, $864 \mathrm{~g}$. ; thyroid, $22.5 \mathrm{~g}$. ; pituitary, $0.65 \mathrm{~g}$.

The heart was greatly enlarged and was rotated to the left, the left ventricle being entirely posterior, and displacing the oesophagus to the right. Both ventricles were dilated and hypertrophied (left, $1.6 \mathrm{~cm}$. thick ; right, $0.5 \mathrm{~cm}$. thick). The aortic valve showed 


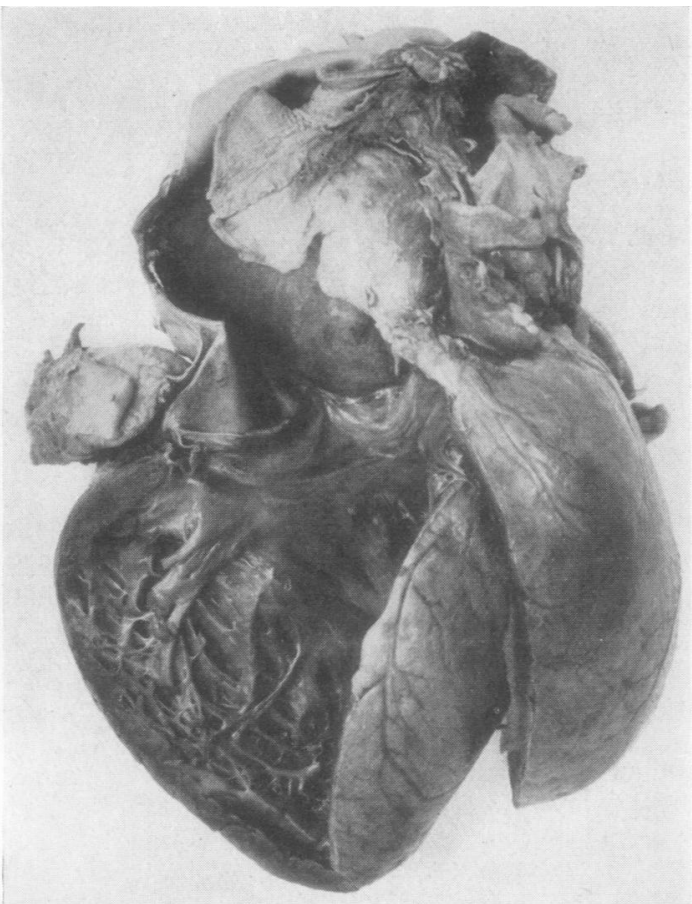

FIG. 1. - Heart in Case 1 opened to show aortic aneurysm and rolled thickenings of the aortic cusps.

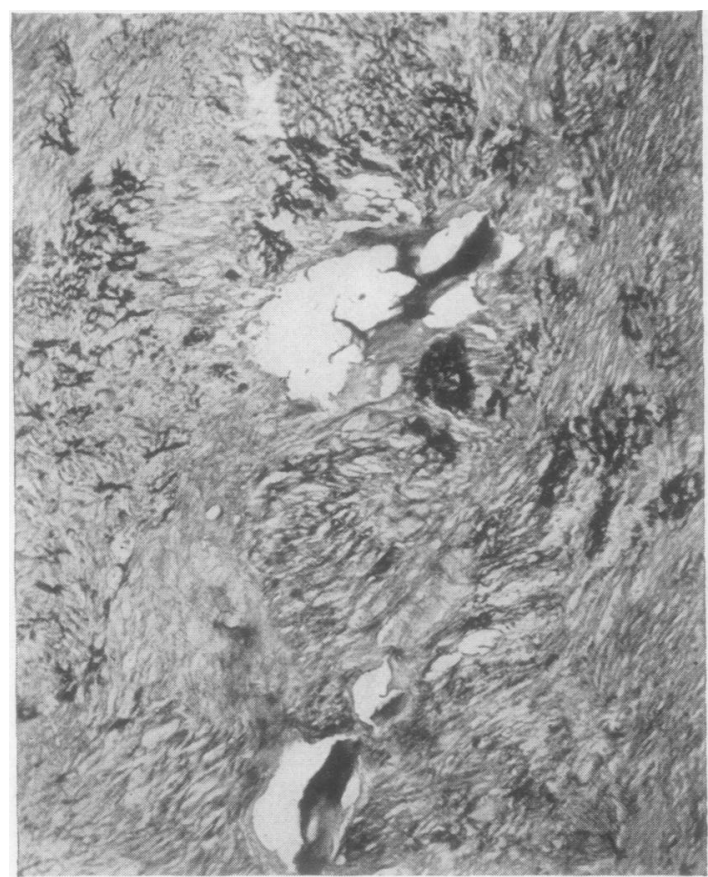

widening of the ring $(10.5 \mathrm{~cm}$. circumference); the aortic cusps (Fig. 1) were translucent, each having a smooth, grey, thickened free border (from 1.5 to $2.5 \mathrm{~cm}$. long by $0.2 \mathrm{~cm}$. diameter). The coronary orifices were situated at the upper limit of insertion of the cusps; the left was duplicated, one of the orifices being pin-head in size. The coronary arteries were otherwise normal.

There was a serous pericardial effusion $(60 \mathrm{ml}$.) and fibrous obliteration of the transverse sinus. The foramen ovale was closed. The mitral, pulmonary. and tricuspid valves were normal.

The aorta (Fig. 1) showed great dilatation in its proximal $6 \mathrm{~cm}$. (circumference up to $19.5 \mathrm{~cm}$.) ; this ended abruptly $4 \mathrm{~cm}$. below the innominate artery. where the circumference was $5.8 \mathrm{~cm}$. The aneurysm showed a conspicuous greyish-white fibrosis of the adventitia. Its lining was mostly smooth and glistening save distally where there were confluent scarred areas, the largest measuring $7 \times 3 \mathrm{~cm}$.: irregular healed fissures extended from these flat. sunken scars into the adjacent intima.

The remainder of the aorta and the carotid. iliac. cerebral, and pulmonary arteries were normal: there were streaks of atheroma in the former. An antemortem thrombus filled the right femoral vein.

Aneurysm Sac.-Sections from the aneurysm sac show severe medial degeneration (Figs. 2 and 3). Io on many areas elastic fibres are either fragmented of destroyed. and reticulin and muscle fibres are absent. There are clefts and cysts filled with basophilic an

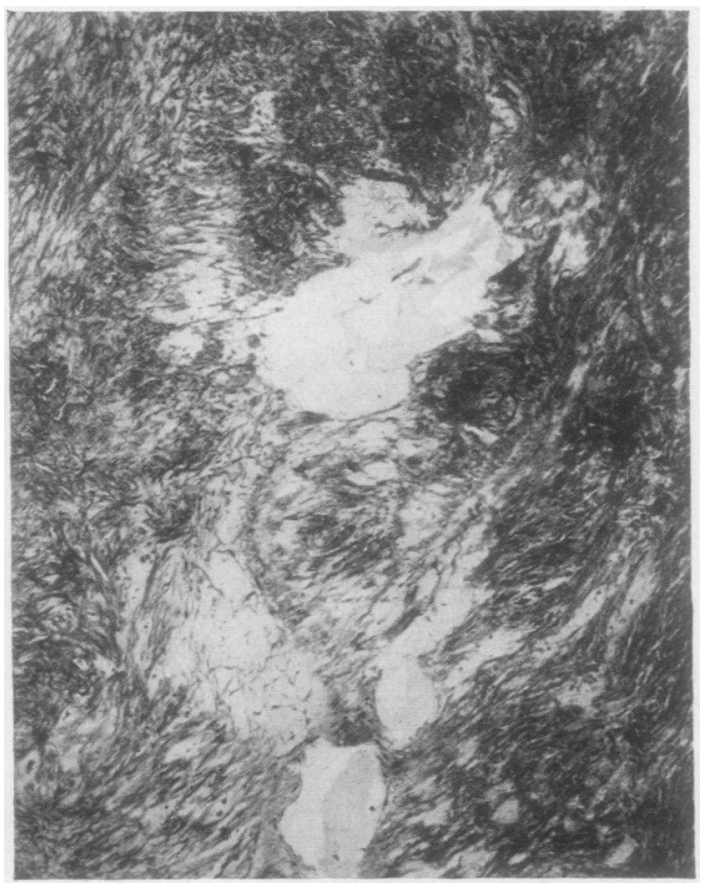

Figs. 2 AND 3.-Adjacent sections from aneurysm sac. Fig. 2.-Cystic medial degeneration, with fragmentation of elastica. Hart's elastic stain . Fig. 3. - Survival of irregularly disposed phloxinophil fibres, possibly muscle fibres. Lendrum's phloxin-tartrazine and celestin-blue, $\times 60$. 
metachromatic fluid. Elsewhere in the media these spaces contain numerous irregularly disposed spindle cells with picrophil and phloxinophil cytoplasm. These cells may be muscle fibres, although they stain poorly with Mallory's phosphotungstic-acid-haematoxylin. In some places the media seems to have been completely destroyed, and the wall is represented by adventitia and greatly hyperplastic intima. In general, however, the intima is not greatly thickened. The sac is covered by a thick, dense, and relatively acellular collagenous adventitia.

Sections from the left common carotid and pulmonary arteries and the descending thoracic aorta are normal.

The Heart.-A section from the mitral cusp of the aortic valve shows the thickening of the free margin to be due in part to fibrosis and in part to oedema, but there is a slight proliferation of connective tissue cells on the contact surface of the valve, and also on its upper surface near its base. The base, however, is neither thickened nor vascularized, nor is there any suggestion here or elsewhere of rheumatic carditis.

There are several areas of myocardial necrosis beneath the endocardium of the left ventricle, some associated with slight lymphocytic infiltration (Fig. 4). These areas have at their centre a cluster of capillaries. Contiguous surviving muscle fibres, some of which

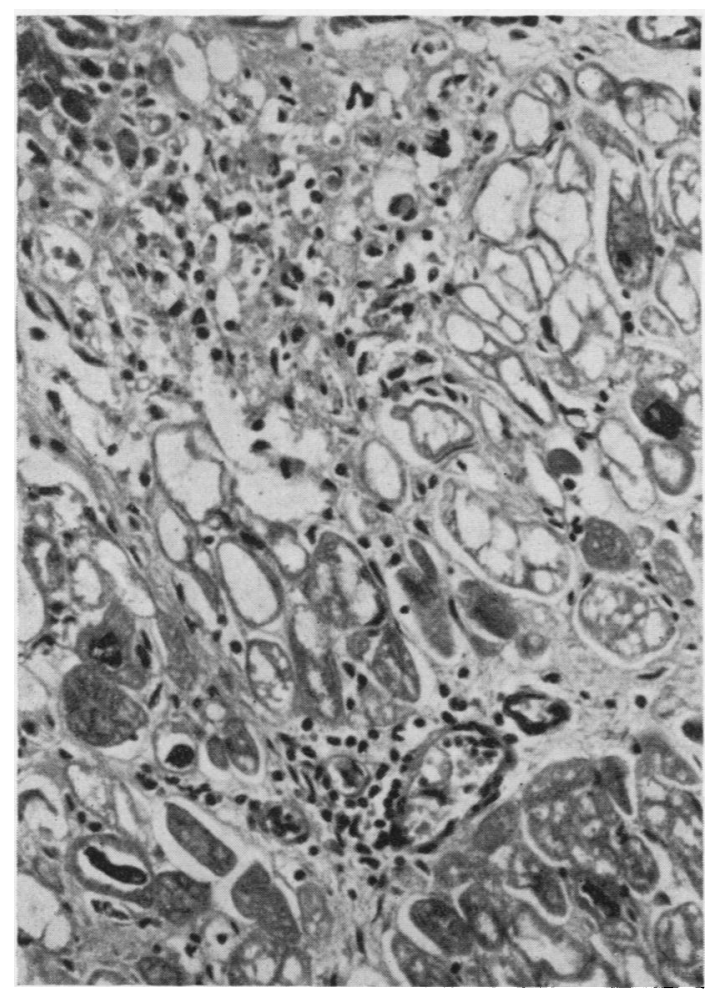

FIG. 4.- Section from left ventricle (Case 1). Sub-endocardial vacuolation and degeneration of muscle fibres with round-celled infiltration. Haematoxylin-eosin, $\times 240$. contain pycnotic and misshapen nuclei, show severe cytoplasmic vacuolation. This may be a hydropic change, or it may be due to fat. The vacuolation is not due to glycogen, which can be demonstrated in normal amounts (Mowry and Bangle, 1951) in the myocardium, nor is it due to any other material demonstrable in paraffin sections by Sudan black or the periodic-acid-Schiff technique. Unfortunately frozen sections of myocardium contain no areas of necrosis.

Other Organs.-The lungs are greatly congested. The thyroid is normal. In the pituitary are two chromophobe adenomas (larger $0.3 \mathrm{~cm}$. diameter). A differential count of 6,146 cells at three horizontal levels reveals $51.7 \%$ to be acidophils, $5.2 \%$ basophils, and 43.1\% chromophobes. Accepting Rasmussen's figures (1933), the proportion of acidophils is high normal.

Case 2.-This woman, aged 55 years, had experienced fainting attacks some 30 years previously, and was informed that she had heart disease. No clinical findings are available. Three months before examination in 1952 she developed shortness of breath. This increased in spite of digitalis, and she developed oedema of the ankles. On examination she was thin, slender, and had long, thin fingers, but her limbs did not seem unduly long, and the eyes were normal. The pulse was regular and collapsing. The blood pressure was $180 / 60 \mathrm{~mm}$. $\mathrm{Hg}$. The apex beat was slightly displaced outwards. There was a systolic murmur at the apex, with an early diastolic murmur and thrill. There was enlargement of the left ventricle on radiological examination, and prominence of the aortic arch. The electrocardiogram showed flat or low $T$ waves in all leads. Breathlessness increased over a period of nine months, and bilateral pleural effusions developed. She was admitted to hospital, but in spite of treatment died one month after admission.

Relevant Findings at Necropsy (P.M. 96, 1952).Necropsy was performed about 14 hours after death, when the chief findings were heart failure, aortic incompetence, and aneurysm of the ascending aorta. The body was that of a thin, wasted woman, with long, slender, tapering digits, the middle finger $11 \mathrm{~cm}$. long, the second toe $5.5 \mathrm{~cm}$. long. The eyes were normal, as were the endocrine glands. The limbs were thin, but seemed of normal proportions.

Ante-mortem thrombus occluded the artery to the upper lobe of the left lung. All the right lung had collapsed, and part of the left. A slightly bloodstained right pleural effusion $(680 \mathrm{ml}$.) and a left serous effusion $(80 \mathrm{ml}$.) were noted. Also seen were a right pneumothorax, back-pressure changes in the abdominal organs, serpiginous ulcers in the sigmoid colon, and argentaffinoma $(1.5 \times 1 \mathrm{~cm}$. $)$ in the ileum, and pitting oedema of the legs.

Weights were as follows: body, $46.3 \mathrm{~kg}$. (length, $1.52 \mathrm{~m}$.) ; heart and aneurysm, $874 \mathrm{~g}$. ; thyroid, $17.3 \mathrm{~g}$. ; ovaries, $5.6 \mathrm{~g}$. ; pituitary, $0.6 \mathrm{~g}$.

The heart was enlarged. Both ventricles were dilated and hypertrophied (the right up to $0.5 \mathrm{~cm}$. thick ; the left up to $1.5 \mathrm{~cm}$. thick). The foramen ovale was closed. There was a gelatinous flat nodule $(0.9 \mathrm{~cm}$. 


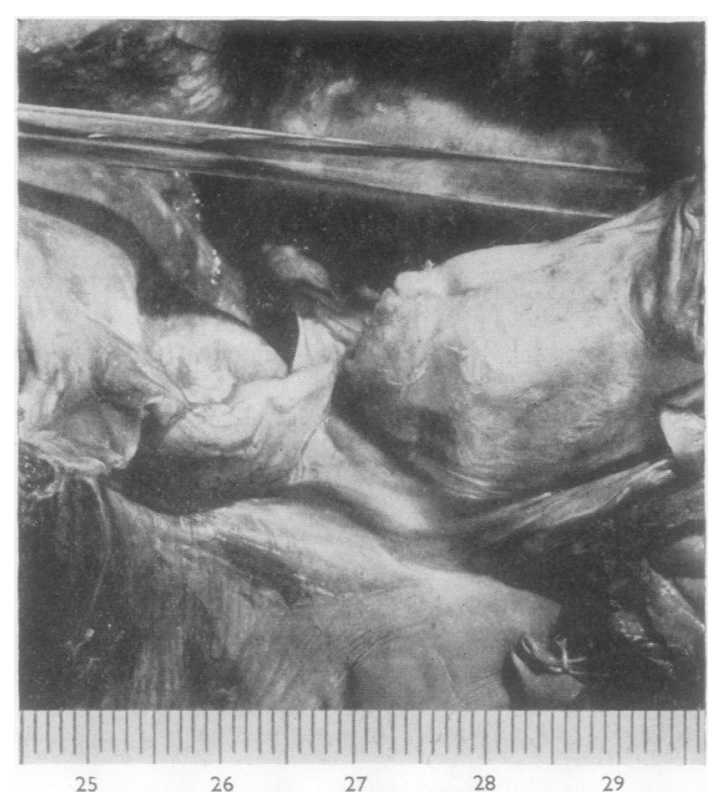

FIG. 5.-Aortic cusps and sac in Case 2, showing thickenings of free margin of cusp.

diameter $\times 0.2 \mathrm{~cm}$. thick) on the septal cusp of the tricuspid valve. The aortic valve was incompetent to water. The cusps were translucent, their free edges (Fig. 5) adjacent to the corpora Arantii being thickened (up to $0.5 \mathrm{~cm}$. long $\times 0.2 \mathrm{~cm}$. thick), with a slight granularity of the contact surface. A similar granularity was present on the contact surface of one mitral cusp. The coronary ostia were situated $1.5 \mathrm{~cm}$. above the commissures.

There was a fusiform dilatation (up to $11.5 \mathrm{~cm}$. circumference) of the ascending arch of the aorta, terminating at the innominate arteries.

The descending thoracic aorta was $6.5 \mathrm{~cm}$. in circumference. There was moderate atheroma, consisting of fatty streaks and thin plaques in the first part of the ascending aorta; more plaques were present in the remainder of the aorta, and one calcified plaque towards its lower end. Nowhere was the intima wrinkled or scarred.

Aneurysm Sac.-Sections from the aortic ring and from the proximal and distal parts of the ascending arch of the aorta show a widespread disorganization of the media, particularly conspicuous near the aortic valve. Where the internal elastic lamina can be identified there is only slight intimal atheroma ; elsewhere the thickness of the intima cannot be assessed. The medial elastic tissue has been focally replaced by rarely fuchsinophil, mainly picrophil, fibres, some probably representing surviving muscle fibres. There are cysts and clefts, some containing metachromatic material. The adventitia is thickened by hyaline fibrosis. There is no lymphocytic infiltration.

Sections from the aortic cusp to one side of the corpus Arantii show a partly fibrous, partly oedema- tous and myxomatous, thickening of the free margin. There is a similar change in the tricuspid valve. On $\frac{\mathrm{O}}{\text {. }}$ the contact surface of the aortic valve there is $a \overrightarrow{\bar{F}}$ proliferation of connective tissue cells, but its base $\stackrel{\text { ? }}{+}$ shows no evidence of rheumatism. Sections from들 the pituitary and thyroid are normal.

\section{Discussion}

In the first case, a woman aged 24 years, then diagnosis of Marfan's disease was fully established. 2 It is of particular interest that the aortic arch was? found radiologically to be abnormally prominent $\vec{\omega}$ 10 years before the recognition of arachnodactyly We think that aortic medial degeneration was already present and the cause of a slight dilatation's which later developed into an aneurysm. We have recently found the same radiological appearance inco a boy aged 9 with arachnodactyly, and suggest that he too may develop an aneurysm.

In our second case, a woman of 55 years, $\vec{z}$ although there was a suggestion of arachnodactyly, the skeletal changes were not otherwise characteristic of Marfan's disease. On the other hand, there were cardiac and aortic lesions which closely resembled those in our first case, and the question $\overrightarrow{0}$ arose as to whether, on the strength of these lesions, she should be regarded as an incompleq case of Marfan's disease.

An aneurysm of the aortic arch due to medral degeneration and without coarctation is indeed highly suggestive of this condition if it occurs in youth. Thus we can find a record of only one such aneurysm in a case without arachnodactyly ando흘 aged less than 40 years (Davies, 1941). Our? patient, however, was aged 55 years, an age at which the cardiovascular complications of Marfan's disease have been recognized (Moses, 1951), but an age at which the non-specificomedial degeneration of senescence might per haps begin to take effect, and itself give rise to aortic aneurysm, as in the cases described by Turnbull and Rottino. This possibility iso difficult to exclude, since there is no histological difference between the two forms of medialo degeneration. For it has long been known that fragmentation of the elastica, loss of muscle fibres, $\mathrm{C}$ and mucoid-filled spaces occur in the arch of the 0 aorta in old age, whether in the presence or absence of aneurysm (Björling, 1911 ; Turnbull, 1915) while the particular features claimed by Baer Taussig, and Oppenheimer (1943) to be peculiar to Marfan's disease, namely, medial " smooth muscles hyperplasia," medial vascularization, and adventitial fibrosis, have all been recognized in appar-oํ․ ently uncomplicated dissecting aneurysms (Gsell, 1928 ; Erdheim, 1930 ; Levinson, 1931). 
The cardiac lesions in our second case included displacement of the coronary ostia and fibromyxomatous valvular thickenings. These, although they both have been recorded in several cases of Marfan's disease (Uyeyama, Kondo, and Kamins, 1947 ; Reynolds, 1950), are not peculiar to this condition ; for the first is a fairly common congenital abnormality, while the second has been reported in a case of coarctation of the aorta in the apparent absence of arachnodactyly (Harrison, 1939).

We have not, however, found any report, save in Marfan's disease, of a case in which such cardiac lesions have been associated with a nonsyphilitic aneurysm of the aortic arch, and for this reason suggest that this combination of lesions is probably peculiar to Marfan's disease.

Fundamental Abnormality in Marfan's Disease. - The explanation for the many abnormalities encountered in this disease is obscure. We suggest that the disturbance in ground substance which is seen in the aorta could be responsible for such diverse lesions as laxity of joints, dislocation of the optic lens, and perhaps even a disturbance in the ossification of long bone. The test of this hypothesis must await the histological examination of ligamentous attachments and of the epiphyses of long bones in typical cases. Meanwhile, it is of interest to speculate whether this hypothetical generalized disturbance in ground substance is primary, or perhaps secondary to some underlying endocrine disease, for certain supposed endocrine lesions have been encountered in Marfan's disease which could lead to the mesenchymal upset we have postulated. First, there is a single report of atrophy of the thyroid (Tobin, Bay, and Humphreys, 1947), which is significant in the light of Kountz and Hempelmann's (1940) observation, namely, that three patients with hypertension developed dissecting aneurysms due to medial degeneration following therapeutic panthyroidectomy. In our cases, however, the thyroid was normal.

Second, it has betn held that there is acidophil cell hyperplasia in the pituitary (Schilling, 1936; Tobin et al., 1947), and indeed, the acidophil percentage in our first case was at the upper limit of normal by Rasmussen's standards (1933). These findings recall the acidophil change in the pituitary in pregnancy and there are certain other curious similarities between pregnancy and Marfan's disease. Thus, in both there is apparently a tendency towards changes in the aortic media. The evidence of this in pregnancy lies in the relatively frequent occurrence of dissecting aneurysm to- wards term (Göbel, 1936; Schnitker and Bayer, 1944). One woman who died thus also had arachnodactyly (Lindeboom and Bouwer, 1949). Again, the widespread laxity of the joints in Marfan's disease has a counterpart in the laxity of the pelvic joints in pregnancy, a change which is known to be mediated through the pituitary and ovaries, and to be accompanied, in the guinea-pig at least, by a depolymerization of ground substance at the symphysis (Perl and Catchpole, 1950), a change akin to mucoid degeneration of the aorta. These similarities suggest that in Marfan's disease there may be a basic disturbance in ground substance due to a primary endocrine disease. This theory is, however, speculative and its proof must await further investigation.

\section{Suimmary}

Two cases of aneurysm of the ascending aorta due to medial degeneration are described.

This rare variety of aneurysm occurs not only in old people but also with a curious frequency in patients with Marfan's disease.

The type of aortic medial degeneration seen in these patients has no specific histological features, but the combination of aortic dilatation, fibromyxomatous thickenings of the free margins of the aortic cusps, and congenital cardiac abnormalities is probably characteristic of Marfan's disease.

The tendency to aortic medial degeneration may reflect a generalized and perhaps hormonally induced disturbance of ground substance.

We wish to thank Dr. William Evans, Professor Dorothy Russell, and also Professor Lendrum for their advice and criticism.

\section{REFERENCES}

Baer, R. W., Taussig, H. B., and Oppenheimer, E. H. (1943). Bull. Johns Hopk. Hosp. 72, 309.

Björling, E. (1911). Virchows Arch. path. Anat., 205, 71

Bjorling, E. (1911). Virchows Arch. path. Anat,

Erdheim, J. (1930). Virchows Arch. path. Anat., 276, 187

Göbel, A. (1936). Zbl. Gynäk., 60, 38.

Gsell, O. (1928). Virchows Arch path. Anat., 270, 1.

Harrison, F. F. (1939). Arch. Path. Chicago, 27, 742.

Kountz, W. B., and Hempelmann, L. H. (1940). Amer. Heart J., $20,599$.

Levinson, B. (1931). Virchows Arch. path. Anat., 282, 1.

Lindeboom, G. A., and Bouwer, W. F. (1949). Cardiologia, Basel, 15,12 .

Marfan, A. B. (1896). Bull. Soc. méd. Hôp. Paris, 3 ser, 13, 220.

Marvel, R. J., and Genovese, P. D. (1951). Amer. Heart J., 42, 814

Moses, M. F. (1951). Brit. med. J., 2, 81

Mowry, R. W., and Bangle, R. (1951). Amer J. Path., 27, 611.

Perl, E., and Catchpole, H. R. (1950). Arch. Path. Chicago, 50, 233

Rados, A. (1942). Arch. Ophthal., Chicago, 27. 477.

Rasmussen, A. T. (1933). Amer. J. Path., 9, 459.

Reynolds, G. (1950). Guy's Hosp. Rep., 99. 178.

Rottino, A. (1939). Arch Path:, Chicago, 27, 320

Rywlin, A. (1952). Frankfurt. Z.' Path., 63, 187.

Schilling, V. (1936). Med. Welt, 10, 183

Schnitker, M. A., and Bayer, C. A. (1944). Ann. intern. Med , 20, 486

Tobin, J. R., Bay, E. B., and Humphreys, E. M. (1947). Arch. intern. Med., 80, 475 .

Turnbull, H. M. (1915). Quart. J. Med., 8, 201. Uyeyama. H., Kondo, B., and Kamins, M. (1947). Amer. Heart J.,
34, 580. 